\title{
Culture-Driven Mortality in Caspian seal (Pusa caspica) at Southern Fringe of Caspian Sea
}

\author{
NIKTA MOGHADDAMIPOUR ${ }^{1}$, PARVIN FARSHCHI', \\ ESMAIL KAHROM ${ }^{1}$ AND MOHAMMAD ALI MAZHARI ${ }^{2}$
}

\author{
${ }^{1}$ Department of Energy and Environment, Science and Research Branch, \\ Islamic Azad University, Tehran, Iran. \\ ${ }^{2}$ Paya Boum Kav Company.
}

http://dx.doi.org/10.12944/CWE.9.1.07

(Received: March 18, 2014; Accepted: April 15, 2014)

\begin{abstract}
Caspian seal (Pusa caspica) is countered as a unique, endangered species, restricted only to the Caspian Sea. High death rate of Caspian seal has been reported owing to chemical infections, extreme concentration of chemical trace elements, organochlorine pollutants, etc. Among numerous possible reasons for mortality of Caspian seals, the role of culture in mortality has always been less-noticed.Accordingly, the present study was put forth by studying the culture of inhabitants at Southern border of Caspian Sea. For this, the behavior of local communities was interviewed. It was observed that Iranian people were not adequately familiar with real worth of different creatures in environment, and considered them as dangerous enemies, or at least annoying. Therefore, when encounter the animals, they attempt to kill, harass, or scare them away. Usually, unidimensional view of financial gain from seals, and excessive fishing of aquatics fed by seals put them in danger of extinction. Over all, In order to gain more consistent findings on this matter, furthur researches are suggested.
\end{abstract}

Key words: Indigenous Culture, Caspian seals, Mortality, Extinction.

\section{INTRODUCTION}

The Caspian seal (Pusa caspica) is one of the smallest members of the earless seal family; uniquely found in brackish waters of Caspian Sea. They can be found not only along the shorelines, but also on the many rocky islands, and floating blocks of ice that dot the Caspian Sea. The Caspian Sea is characterized by different variations in its base level during the late Cenozoic period, and provides important sources for long-term records of regional climate due to its location within the interior of the Eurasian region'. Complex systems such as large ecosystems, e.g. the Caspian Sea, have mechanisms to spontaneously overcome the problems arisen in the system, and its components, and return the ecosystem to its original state.
However, in many cases when human interferes with natural ecosystems and causes problems, these regulatory mechanisms cannot overcome human manipulation, which are often severe, and thus fail to offset or reduce damages. Sharma et al. (2014) stated that strong deterioration of environment and human health, which is, as a result of persistent organic pollutants, have been used in a wide range of agricultural and industrial supplies ${ }^{2}$. A number of studies on the occurrence of persistent organic pollutants confirm their presence in various environmental components and human body.

Pusa caspica is a unique endangered species, that is found exclusively in the Caspian Sea (Figure 1); 


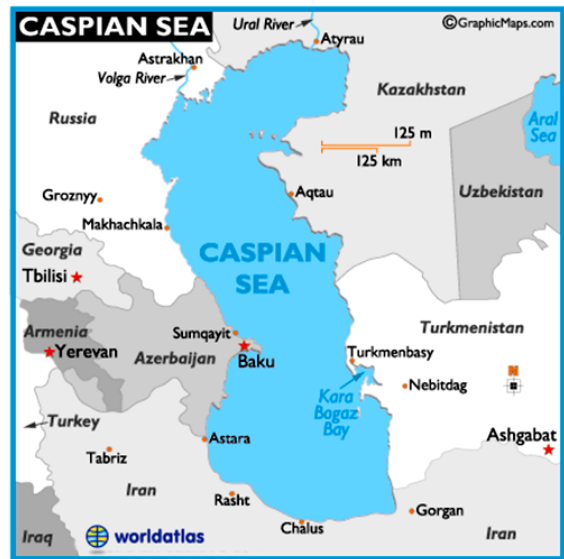

Fig. 1: Location of Caspian Sea

It is not clear till date how many seals survive in the Caspian Sea. Of one million seals during twentieth century, only $1,10,000$ to $3,50,000$ seals are predicted to inhabit the region now-adays (Figure 3).

Indigenous culture seems to be one of the main reasons for extinction of Caspian seal (Pusa caspica) (1)Cherry (2008) stated that humans tend to misbehave as animals in numerous ways, both deliberately and unconsciously. Deliberate harshness towards animals is counted as violent ethics. It's worth mentioning that the "normal" acts that to animals like clothing, entertainment, and clinical trials can also be considered as a violence. The development may also portend animal habitats,

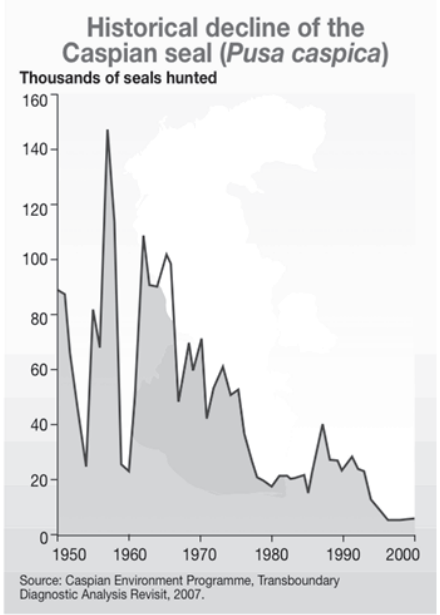

Fig. 3: Historical Decline of Caspian seal (Pusa caspica) mention source

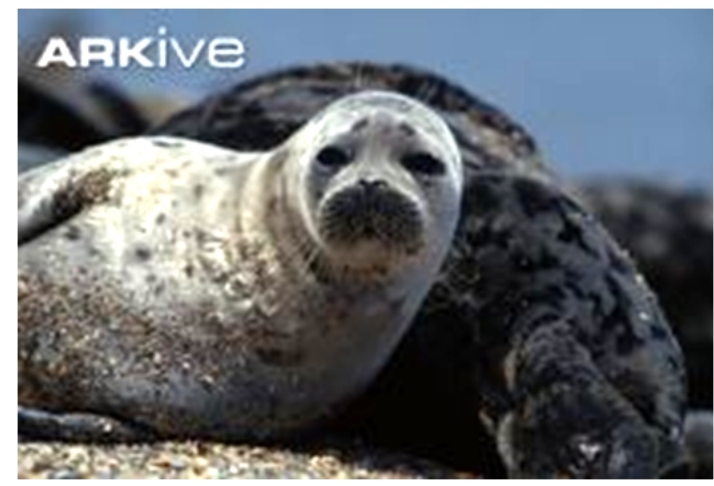

Fig. 2: Caspian seal

causing extinction or endangerment of certain species $^{2}$

Baenninger (1991) examines historical aspects of violence, aggression, and cruelty to certain species. General treatment of animals to humans and vise versa is described. From sociobiological point of view, human predation, competition, or parasitism, cannot be considered as harshness and cruelty, unless these actions do not benefit humans or humanity. The other kind of interactions with other species has made possible varieties of violence that eventually produced restraining legislation in modern and industrial societies. The determinants of cruelty to animals, defined as intentional injury by an aggressor believes that animals share some human experiences and derive no benefit from the aggression $^{3}$

The current culture of the Iranian society is such that people assume human apart from the nature, and its associated components; animate and inanimate ${ }^{5}$. They are unaware that human survival depends on the nature's balance. As a result, not only do they attempt to maintain the balance and their sodality with the nature, but also themselves undisputed owners of the nature, and see the land as their exploitation and dissipation area ${ }^{4}$ Human activities, today have generally, destroyed or severely disturbed many habitats, and only a few of these habitats have remained, while the number of habitats in which seals were concentrated was much higher ten years ago ${ }^{6}$ 
Habitat destruction may reduce the fertility, and hence population. It can even make seals more vulnerable to threats ${ }^{7}$ Declining populations of marine mammals including seals, virtually has disrupted the entire ecosystem. This article has identified the role of indigenous cultural conditions of Iranian society as a major cause of abnormal death of Caspian seal (Pusa caspica), and their population decline in order to be of an extensive help for the preservation of these valuable but vulnerable species.

\section{Public culture}

People of different communities deal differently with their surrounding phenomena, that is based on the conditions of the society where they live, such as historical, religious, and economic conditions as well as customs and norms ${ }^{8}$ Although, it is obvious that there is no common cultural changing pattern, the direction of change has been devastatingly changing toward complexity ${ }^{9}$ Iranian people are among those communities with no proper behavior with the nature and natural surrounding phenomena. It can be generally said that they will be hostile with any creature that does not meet their needs, without hesitating a little about the reasons for their behavior ${ }^{10}$ As noted before, the reason is rooted in multiple social and cultural conditions and factors, which are beyond the scope of this article. Examples of such behavior are repelling birds, cats, and dogs or killing snakes and even insects that are sometimes beneficial. These violent behaviors are such that even animals in

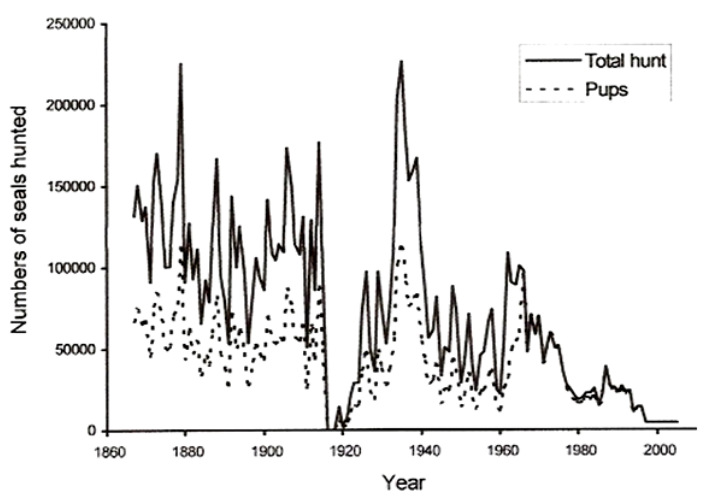

Fig. 4: Total registered harvest of Caspian seal (Pusa caspica) (solid line) and the number of pups (dashed line) (1867-2005) mention source urban areas run as soon as people get close to them. These animals are considered semi-domestic and are seen in areas of high traffic and in close distance to humans in other countries like countries in Europe and etc. They even easily snatch food from people. For instance, there are pigeons in the squares and parks of European cities such as London. Even more interestingly, such violent behaviors against animals are not even observed in the children in these cities; this is evident that children are properly trained on that matter. This peaceful coexistence is rarely seen in Iran. Gullone and Robertson (2008) assessed the simultaneous engagement in animal abuse, and bullying behavior in 241 youngsters aged between 12 to 16 years. It was concluded that witnessing animal abuse was predictive which is both supportive of past research and authorizes further research attention. The findings have significant suggestions for the prevention and mediation of bullying and animal abuse behaviors ${ }^{11}$

\section{General Education}

Learning plays an important role in how the human being confronts various issues; Animal comfort laws in many countries require housing and treating animals in such a way that all of their species-specific needs can be satisfied and that they are not vulnerable to stress or pain ${ }^{12}$, so that advanced countries have changed cultural factors such as some wrong values and norms, and even have built culture through proper planning in public education sector and succeeded. However, actions taken in Iran's public education are not suitable for making changes in overall view of people, regarding the nature and its living creatures, and people still consider themselves apart from nature and its components, and exert a self-centered and inhumane attitude towards them. However, the human being is certainly a part of the nature and the institutionalization of this view among people can be a major step towards the preservation of the nature.

\section{Vocational training}

Vocational training is a key factor in occupations. In other words, it is transferring all necessary knowledge, skills, and attitudes to individual for accurate performance of the tasks. Vocational training includes all side issues that are 
somehow associated with that profession, as well as issues surrounding the workplace. However, vocational training is not fully implemented in Iran because such training is not yet known in many jobs and even employers are completely unfamiliar with it. In some jobs with such trainings, not all employees benefit from it due to lack of facilities. Moreover, since this type of education have not been fully settled in Iran, the presented entries are not typically comprehensive and only technical aspects of the profession are discussed and not all aspects of the job. Finally, practitioners are not completely aware of their jobs and their relating issues.

\section{The attitude and behavior of hunters as a group} of people in the community

As a group of Iranian people, undoubtedly hunters possess the general characteristics of the community including culture, public education, and vocational training. The impact of hunting is often assumed to contain the high percentage of species (26.4\%) listed as threatened with extinction in the IUCN Red Lis ${ }^{13}$.In particular, social deficits are evident usually in lower social classes and hunters, as a group of people with mostly a degree of under high school diploma whose income from hunting cannot answer all their financial needs, are not exempt from this rule. According to what was said, erroneous views about the nature and its components have clearly penetrated among hunters of our society. Figure 4 shows the total hunting of Caspian seal (Pusa caspica) in recent years. As it can be seen, the culture of hunting has been changed over the past decades ${ }^{14}$

\section{Officials' culture}

The most essential factor for discipline, progress, and sustainable development in a community is the establishment of a system of scientific and efficient management at all decisionmaking and executive levels in the society. Therefore, countries with defects in these areas encounter numerous problems during their development. One of the most important problems is environmental issues which often arise from the lack of coordination between development programs and environmental conditions. In our country, evidence shows that the directors and officers of various departments have failed to take right decisions for dealing with these problems because they are part of the people of this community with educational and cultural conditions of the society, as mentioned. According to figures from the Iranian media, about $\$ 40$ billion is lost annually due to poor decisions made by managers. As it was mentioned, although environmental issues are important, officials, directors, and employees are inattentive and indifferent even to the scope of their responsibility for environmental issues for reasons explained earlier and they do not prioritize these problems and do not feel responsible for them.

\section{CONCLUSION}

Iranian people are not adequately familiar with environmental phenomena and consider other creatures as dangerous enemies, or at least annoying. Therefore, when encountering them, they attempt to kill, harass, or at least scare them away. Officials are indifferent to environmental issues due to the lack of responsibility and unawareness of their duties and thus they do not attempt to prevent and resolve problems in this regard.

As a group in this community, hunters behave like most people when they encounter creatures in the environment, especially when they disturb their work and livelihood. In this case, this behavior is far more violent and more serious by hunters. Therefore, we cannot deny the relationship between the culture of the community in general and the behavior of hunters in particular and the deaths of seals.

\section{ACKNOWLEDGEMENT}

We would like to express our sincere gratitude for the services rendered by Ravian Danesh Modit Company (Ravian D.M.) in providing insightful comments and proof-reading of the manuscript. 


\section{REFERENCES}

1. Glenn R. Van Blaricom, Leah R. Gerber, Robert L. Brownell Jr. Encyclopedia of Biodiversity,, $2^{\text {nd }}$ edition , 64-93 (2013)

2. Cherry E, Jasper J. M.., Encyclopedia of Violence, Peace, \& Conflict $.2^{\text {nd }}$ edition, 6474(2008)

3. Baenninger R, Adv Phsychol., 76: 5-43 (1991)

4. Hoffman D.M., Int $j$ Intercult Rel., 14: 275299 (1990)

5. Arefi. M, City, Culture and Society., 4: 37-48 (2013)

6. Nakagiri. N, Sakisaka. Y, Togashi .T, Morita .S, Tainaka .K, Ecol Inform., 5: 241-247 (2010)

7. Ovaskainen .O, Math Biosci., 181: 165-176 (2003).
8. Reisinger. Y, International Tourism, 263288(2009)

9. Goucher. C, LeGuin.Ch, and Walton.L, selections from chapter 2, "Changing Environments, Changing Societies."

10. O. Jones. International Encyclopedia of Human Geography, 2009: 309-323.

11. Gullone. E, Robertson. N, J Appl Dev Psychol., 29: 371-379 (2008)

12. Keane. A, Brooke. M.de L, Mcgowan. P.J.K, Biol Conserv, 126: 216-233(2005)

13. GRID-Arenda,I Historical decline of the Pusa caspica(Pusa caspica), ,Caspian Sea - State of Environment 2011

14. Harkonen T, Harding KC, Wilson S, Baimukanov M, Dmitrieva L, et al. PLoS ONE., 7,e43130,(2012). 